Head and Neck Cancer

\title{
Evaluation of Salivary Lactate Dehydrogenase as a Prognostic Biomarker in Tobacco Users with and without Potentially Malignant Disorders of the Oral Cavity
}

\author{
Rashmi Kademadkal Javaraiah ${ }^{1} \quad$ Chaya Manoranjini David ${ }^{2}$ J. Namitha ${ }^{2}$ Ritu Tiwari ${ }^{2}$ \\ Prabhavati Benakanal ${ }^{3}$ \\ ${ }^{1}$ Department of Dentistry, Kanva Sri Sai Hospital, Bengaluru, \\ Karnataka, India \\ 2Department of Oral Medicine and Maxillofacial Radiology, \\ Dayananda Sagar College of Dental Sciences, Bengaluru, \\ Address for correspondence Ritu Tiwari, BDS, MDS, Department of \\ Oral Medicine and Maxillofacial Radiology, Dayananda Sagar College of \\ Dental Sciences, Shavige Malleshwara Hills, Kumaraswamy, \\ Bengaluru 560078, Karnataka, India (e-mail: tiwari.ritu28@gmail.com).
} Karnataka, India

${ }^{3}$ Department of Oral Medicine and Maxillofacial Radiology,

Sharavathi Dental College, Shimoga, Karnataka, India

Abstract

Keywords
- lactate dehydrogenase
- oral cancer
- prognosis
- saliva
- tobacco

Background Oral squamous cell carcinoma (OSCC) is a deadly disease that develops in a multistage process and is often preceded by oral potentially malignant disorders (PMDs), of which many are caused by tobacco usage. It is associated with a shift from an aerobic to anaerobic glycolytic pathway, and hence an increase in lactate dehydrogenase (LDH) levels is seen. The objective of this study was to estimate and correlate the level of salivary LDH in healthy individuals with tobacco users (with or without PMDs).

Methods A total of 78 patients were selected from the Department of Oral Medicine and Radiology, Dayananda Sagar College of Dental Sciences, Bengaluru, Karnataka, India, and were divided into three groups of 26 patients each, namely controls, tobacco users without PMD, and tobacco users with PMD. A total of $1 \mathrm{~mL}$ of unstimulated saliva was collected from each patient using the spit method. Sample was subjected to centrifugation at 2,500 rpm, and salivary LDH was quantified by a standard kit (LDH-P kit, DIALAB, Neudorf, Austria) using an autoanalyzer.

Results There was a statistically significant $(p<0.001)$ gradual increase in the level of $\mathrm{LDH}$ in controls ( $267 \pm 27.64 \mathrm{U} / \mathrm{L})$, tobacco users without PMD $(391 \pm 80.53 \mathrm{U} / \mathrm{L})$, and tobacco users with PMD (706.1 $\pm 199 \mathrm{U} / \mathrm{L})$. Increase in the LDH level was also noted with increased duration and frequency of the habit.

Conclusion LDH can potentially be used as a promising biomarker in the very early stages of progression toward oral cancer caused by tobacco use.

DOI https://doi.org/ $10.1055 / \mathrm{s}-0040-1721174$ ISSN 2278-330X. (c) 2020. MedIntel Services Pvt Ltd.

This is an open access article published by Thieme under the terms of the Creative Commons Attribution-NonDerivative-NonCommercial-License, permitting copying and reproduction so long as the original work is given appropriate credit. Contents may not be used for commercial purposes, or adapted, remixed, transformed or built upon. (https://creativecommons.org/licenses/by-nc-nd/4.0/)

Thieme Medical and Scientific Publishers Pvt. Ltd., A-12, 2nd Floor, Sector 2, Noida-201301 UP, India 


\section{Introduction}

Oral cancer is the sixth most common human malignancy causing major global public health problems with a 5 -year mortality rate of approximately $50 \%{ }^{1,2}$ Around $90 \%$ of these are oral squamous cell carcinomas (OSCCs). ${ }^{3}$ OSCC is a multistage process and is often preceded by oral potentially malignant disorders (PMDs). The global prevalence of oral PMD has been reported at 1 to $5 \%{ }^{4}$ However, in India and other Asian countries, there is particularly high prevalence, which is being attributed to the influence of region-specific factors, especially tobacco and betel quid chewing.

Tobacco has been used in India for centuries. More than 7,000 different chemicals have been identified in tobacco and tobacco smoke, of which 60 are recognized to be carcinogenic. An alarming increase in the incidence rate of OSCC has been noted in the younger population, which can be attributed to the heavy use of tobacco and tobacco-related products and the ease with which they are available. ${ }^{5}$

At present, diagnosis of the condition rests heavily on screening by visual examination along with the use of tools such as vital staining with toluidine blue dye, brush biopsy, chemiluminescence, tissue autofluorescence, and tissue biopsy, which is considered the gold standard for establishing the diagnosis. However, with an improved understanding of the molecular aspects of the mechanisms involved in carcinogenesis and advanced technology, there has been a dramatic shift from histopathological to molecular methods of disease diagnosis. ${ }^{6}$

The advent of molecular analysis methods has reiterated the concept of "field cancerization." By definition, it refers to a group of genetically altered clone of cells in the mucosa, which can give rise to synchronous or metachronous tumors or PMDs. The oral cavity is particularly susceptible to this process due to direct contact between the mucosa and the environmental carcinogens. The field effect can explain the episodes of recurrences after tumor resection and the "second primary tumors." The recognition of this "field," which is predisposed to the development of cancer or PMD, depends on the identification of molecular signatures in a genetically transformed but histologically sound field called "peritumoral cancer field." Hence, a reliable tumor marker will not only help diagnose the presence of cancer/PMD but also aid in monitoring the progression and averting transformation of PMDs to invasive cancers.?

Oral cancers and PMDs are constantly bathed in the saliva, enabling direct contact, and this makes the search for molecular markers in saliva a sensible alternative to serum or tissue testing. Recent emphasis on sensitive and specific markers in the saliva is also due to the fact that it is comparatively inexpensive, noninvasive, easy, and safe, thereby increasing patient compliance with repeated testing. Numerous salivary markers have been studied and quantified in different studies for the early detection of OSCC. ${ }^{8-10}$ One among them is lactate dehydrogenase (LDH), which is a ubiquitous enzyme present almost in every cell of the human body.

Within the cell, pyruvate is the end product of the glycolysis pathway, which uses glucose as the principal entity. Under aerobic conditions, pyruvate enters the mitochondrial matrix, where it is oxidized into acetyl-CoA and enters the citric acid cycle. However, in cases such as malignancy and PMDs, due to an anaerobic environment, pyruvate is reduced to lactate in a reversible reaction catalyzed by LDH. This reaction also needs nicotinamide adenine dinucleotide (NAD) coenzyme as a hydrogen acceptor. Increased LDH activity is due to genomic changes during carcinogenesis, which is associated with increase in mitotic index and more lactic acid production by tumor cells by breakdown of glycoprotein. Therefore, its extracellular presence is always related to cell necrosis and tissue breakdown. ${ }^{11}$ It is well established that the levels of salivary LDH are increased in OSCC and oral PMDs. The aim of this study was to estimate the levels of LDH in tobacco users with and without PMDs and to evaluate LDH as a prognostic biomarker, thus enabling the preventive interventions early in the course of the disease.

\section{Materials and Methods}

A comparative clinical study was performed with 78 patients selected from the Department of Oral Medicine and Radiology, Dayananda Sagar College of Dental Sciences, Bengaluru, Karnataka, India. The patients were segregated into three groups of 26 patients each: group A, which was the control group comprising normal healthy individuals between 25 and 60 years of age, group B, which comprised tobacco users without PMD, and group $C$, which comprised tobacco users with clinically and histopathologically diagnosed leukoplakia (16) and clinically diagnosed oral submucous fibrosis (OSMF) (10).

Patients treated for cancer (surgery, chemotherapy, and radiotherapy) and who had a history of systemic diseases known to increase serum LDH levels, such as myocardial infarction, liver diseases, renal disease, and muscular dystrophy, were excluded from the study. Patients with periodontitis were included following a 2-week periodontal therapy.

History of the patients was recorded on a preformatted case sheet, and informed consent was obtained before collecting the sample and also before doing any investigative procedure. Care was taken to see that the volunteers did not consume food or chew gum at least 1 hour before and smoke at least 3 hours before the saliva collection procedure.

Unstimulated whole saliva measuring $1 \mathrm{~mL}$ was collected using the spit method, wherein the patient was asked to comfortably sit in the dental chair with head tilted forward and instructed not to speak, swallow, or do any head movements during the procedure. The patient was asked to spit the pooled saliva into a sterile container. This was transferred to a centrifugation tube, which was transported to the laboratory in a Thermocol box along with an ice pack.

The sample was subjected to centrifugation at 2,500 rpm for 15 minutes, and the supernatant was collected and stored in the refrigerator at $4^{\circ} \mathrm{C}$ until the test was performed. LDH was measured using a standard kit according to "optimized standard Deutsche Gesellschaft fur Klinische Chemie (DGKC) method"12 using a semi-automated autoanalyzer (Chem-7 Semi-Automated Analyzer, Erba Mannheim). 
Principle of the Technique Used to Measure Lactate Dehydrogenase in Saliva

Name of the Kit

The LDH-P kit (DIALAB, Neudorf, Austria) was used.

\section{Principle}

LDH was estimated using the DGKC method.

According to this, LDH catalyzes the following reaction:

$$
\text { LDH pyruvate }+\mathrm{NADH}+\mathrm{H}+\rightarrow \text { L-Lactate }+\mathrm{NAD}+
$$

Decrease of the absorbance value at $340 \mathrm{~nm}$ due to the $\mathrm{NADH}$ oxidation to NAD+ is directly proportional to the enzyme activity.

The kit consists of two reagents (reagent $A$ and reagent $B$ ), with the main component of reagent $A$ being pyruvate and that of reagent $B$ being NADH. Preparation of the test sample and the procedure is explained as follows:

- 10 parts of reagent A and 1 part of reagent B was mixed to obtain the working reagent (e.g., $1,000 \mu \mathrm{L}$ of reagent $A+100 \mathrm{~mL}$ of reagent $B$ ).

- $1000 \mu \mathrm{l}$ of working reagent was pipetted into disposable cuvettes.

- Prepared solution was incubated at $37^{\circ} \mathrm{C}$ for 5 minutes

- $20 \mu \mathrm{L}$ of saliva sample was added.

- The mix was incubated at $37^{\circ} \mathrm{C}$. After 1 minute, the sample was subjected to the autoanalyzer.

- The absorbance $(A)$ was read at $340 \mathrm{~nm}$.

- The absorbance (A) was read again at 1, 2, and 3 minutes thereafter and $\Delta \mathrm{A} / \mathrm{min}$ was calculated.

LDH level was measured in international units per liter (IU/L). The data were then entered into a Microsoft Excel spreadsheet and analyzed using SPSS software (Version 22.0, IBM Corp., Armonk, New York, United States).

\section{Results}

In our study, we observed that there were more males in the $<35$ years of age group who used tobacco. One-way ANOVA was applied to compare the values in three study groups. The salivary LDH levels obtained were $267 \pm 27.64 \mathrm{U} / \mathrm{L}, 391$ $\pm 80.53 \mathrm{U} / \mathrm{L}$, and $706.1 \pm 199 \mathrm{U} / \mathrm{L}$ in controls, tobacco users without PMD, and tobacco users with PMD, respectively. The values were found to be gradually increasing from controls to tobacco users without PMD to tobacco users with PMD and were statistically significant $(p<0.001)$. To compare the salivary LDH levels among the different subgroups, post-hoc Tukey test was performed, and the $Q$ value was calculated by referring to the standardized range statistic table looking up the $q$ value for an $\alpha$ of 0.05 . It was observed that the $q$ value was the highest for the controls versus the tobacco with PMD group, and the differences in LDH values obtained between the different groups were statistically significant ( - Table $\mathbf{1}$ ).

To evaluate the effect of duration of the habit on the level of $\mathrm{LDH}$, the sample was divided into three groups, that is, patients consuming tobacco for $<5$ years, between 5 and 10 years, and $>10$ years. We found an increase in the level of LDH with increased duration in both groups B and C. However, it was much more in those with PMD who used

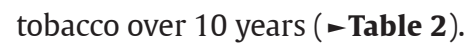

To evaluate the effect of frequency of tobacco habit on the level of LDH, the sample was divided into three groups, that is, patients who consumed tobacco one to four times per day, four to eight times per day, and more than eight times per

Table 1 Post-hoc Tukey test/Tukey's multiple comparison test between different groups

\begin{tabular}{|l|l|l|l|l|}
\hline Category & Mean difference & $Q$ & $\begin{array}{l}\text { Significance } \\
(p<0.05)\end{array}$ & $\begin{array}{l}\mathbf{9 5 \%} \mathrm{Cl} \text { of } \\
\text { difference }\end{array}$ \\
\hline Controls vs. tobacco without PMD & -124.0 & 5.058 & Yes & -207.0 to-40.92 \\
\hline Controls vs. tobacco with PMD & -439.1 & 17.91 & Yes & -522.2 to-356.1 \\
\hline Tobacco without PMD vs. tobacco with PMD & -315.1 & 12.86 & Yes & -398.2 to-232.1 \\
\hline
\end{tabular}

Abbreviations: $\mathrm{Cl}$, confidence interval; $\mathrm{PMD}$, potentially malignant disorder.

Note: $p \leq 0.01$.

Table 2 Comparison effect of duration of tobacco habit on lactate dehydrogenase level (ANOVA)

\begin{tabular}{|c|c|c|c|c|c|c|}
\hline Group & $\begin{array}{l}\text { Duration of the habit } \\
\text { (years) }\end{array}$ & $n$ & Mean \pm SD & $\begin{array}{l}\text { Mean } \\
\text { square }\end{array}$ & $F$ & Significance \\
\hline \multirow{4}{*}{$\begin{array}{l}\text { Tobacco } \\
\text { users } \\
\text { with PMDs }\end{array}$} & $<5$ & 7 & $54,972 \pm 138.68$ & \multirow[t]{4}{*}{$227,669.1$} & \multirow[t]{4}{*}{9.702} & \multirow[t]{4}{*}{0.001} \\
\hline & $5-10$ & 6 & $604.08 \pm 149.45$ & & & \\
\hline & $>10$ & 13 & $8,367 \pm 161.40$ & & & \\
\hline & Total & 26 & $70575 \pm 199.50$ & & & \\
\hline \multirow{4}{*}{$\begin{array}{l}\text { Tobacco } \\
\text { users } \\
\text { without } \\
\text { PMDs }\end{array}$} & $<5$ & 5 & $331.14 \pm 78.89$ & \multirow[t]{4}{*}{$15,942.85$} & \multirow[t]{4}{*}{2.816} & \multirow[t]{4}{*}{0.081} \\
\hline & $5-10$ & 6 & $371.28 \pm 46.28$ & & & \\
\hline & $>10$ & 15 & $418.85 \pm 82.21$ & & & \\
\hline & Total & 26 & $391.00 \pm 80.52$ & & & \\
\hline
\end{tabular}

Abbreviations: ANOVA, analysis of variance; PMDs, potentially malignant disorders; SD, standard deviation. 
Table 3 Comparison of effect of frequency of tobacco on salivary lactate dehydrogenase level among tobacco users with and without potentially malignant disorder (ANOVA)

\begin{tabular}{|c|c|c|c|c|c|c|}
\hline Group & $\begin{array}{l}\text { Frequency } \\
\text { (times/day) }\end{array}$ & $n$ & Mean \pm SD & Mean square & $F$ & Significance \\
\hline \multirow{4}{*}{$\begin{array}{l}\text { Tobacco users } \\
\text { with PMDs }\end{array}$} & $1-4$ & 4 & $494.12 \pm 55.58$ & \multirow[t]{4}{*}{$205,374.8$} & \multirow[t]{4}{*}{8.148} & \multirow[t]{4}{*}{0.002} \\
\hline & $4-8$ & 12 & $657.98 \pm 187.57$ & & & \\
\hline & $>8$ & 10 & $848.66 \pm 14274$ & & & \\
\hline & Total & 26 & $706.11 \pm 199.04$ & & & \\
\hline \multirow{4}{*}{$\begin{array}{l}\text { Tobacco users } \\
\text { without PMDs }\end{array}$} & $1-4$ & 13 & $382.44 \pm 66.31$ & \multirow[t]{4}{*}{$2,649.074$} & \multirow[t]{4}{*}{0.389} & \multirow[t]{4}{*}{0.682} \\
\hline & $4-8$ & 8 & $38678 \pm 107.85$ & & & \\
\hline & $>8$ & 5 & $420 \pm 75.18$ & & & \\
\hline & Total & 26 & $391.00 \pm 80.52$ & & & \\
\hline
\end{tabular}

Abbreviations: ANOVA, analysis of variance; PMDs, potentially malignant disorders; SD, standard deviation.

Table 4 Distribution of salivary lactate dehydrogenase values among tobacco users (with and without potentially malignant disorder) on the basis of the habits (ANOVA)

\begin{tabular}{|c|c|c|c|c|c|c|}
\hline Group & $\begin{array}{l}\text { Type of tobacco } \\
\text { habit }\end{array}$ & $n$ & Mean \pm SD & Mean square & $F$ & Significance \\
\hline \multirow{4}{*}{$\begin{array}{l}\text { Tobacco users } \\
\text { with PMD }\end{array}$} & Cigarette & 3 & $1002.16 \pm 69.50$ & \multirow[t]{4}{*}{$299,167.8$} & \multirow[t]{4}{*}{17.55} & \multirow[t]{4}{*}{$<0.001$} \\
\hline & Chewable tobacco & 16 & $591.84 \pm 130.18$ & & & \\
\hline & Combination & 7 & $840.52 \pm 146.16$ & & & \\
\hline & Total & 26 & $706.14 \pm 199.03$ & & & \\
\hline \multirow{4}{*}{$\begin{array}{l}\text { Tobacco users } \\
\text { without PMD }\end{array}$} & Cigarette & 12 & $393.66 \pm 63.74$ & \multirow[t]{4}{*}{156.97} & \multirow[t]{4}{*}{0.022} & \multirow[t]{4}{*}{0.978} \\
\hline & Chewable tobacco & 11 & $390.45 \pm 103.46$ & & & \\
\hline & Combination & 3 & $382.33 \pm 70.51$ & & & \\
\hline & Total & 26 & $391 \pm 80.50$ & & & \\
\hline
\end{tabular}

Abbreviations: ANOVA, analysis of variance; PMD, potentially malignant disorder; SD, standard deviation.

day. In all three of the groups, the level of LDH was gradually increasing with increased frequency. However, it was much more in PMD patients who consumed tobacco more than eight times per day (-Table 3 ).

On comparing the effect of type of tobacco habit on $\mathrm{LDH}$ level, smokers showed a higher LDH level when compared with chewable tobacco users ( $\mathbf{- T a b l e ~} 4$ ). Values were significant in the tobacco users with PMD group, whereas tobacco users without PMD group did not show much difference in the LDH level. On comparing the effect of type of PMD on LDH level, higher values were observed in the leukoplakia group when compared with OSMF.

\section{Discussion}

Tobacco-related cancers represent the most preventable form of cancer in our society. Incidentally, a majority of tobacco-related cancers occur in the oral cavity, which highlights its potential for easy and early detection..$^{13}$ The main reason behind including the group of tobacco users without PMD in our study was to evaluate any biochemical changes that can be identified in an early stage and also to identify the patients at increased risk in which preventive measures can be instituted. Although 95\% of oral cancers occur in individuals older than 40 years, there has been an increase in the incidence of oral cancer in people younger than 40 years from $3 \%$ in 1973 to $6 \%$ in $1993 .{ }^{14,15}$ In our study, tobacco usage was more in individuals with less 35 years of age. This might be because of various reasons such as the dawn of attractive, conveniently packed sachets, and mass media advertising. Furthermore, products such as gutkha and pan masala are available in every nook and corner, and tobacco usage is being openly professed as a mark of social acceptance.

In our study, we observed that all the patients in tobacco users group were males. High proportion of cases among males may be due to a high prevalence of tobacco consumption in all forms among males; however, this trend is changing. Comparatively, females in Indian society indulge less in tobacco habits. The Global Adult Tobacco Survey India 2009-2010 has substantiated this fact. The report revealed that the prevalence of overall tobacco use among Indian males is $48 \%$ and that among Indian females is $20 \%{ }^{16}$

In our study, we selected saliva as a diagnostic medium, which is a new concentration of research. Saliva is a dynamic and complex fluid made up of secretions of major and minor salivary glands along with gingival crevicular fluid and is useful for the detection of physiological and pathological states of the body. It can provide a host of important information due to lesser amount of complexes as compared with blood and lesser concentration of normal material and 
inhibitory substances. Salivary genomics and proteomics have garnered much interest in the field of oncology, and numerous salivary markers have been successfully isolated and studied. ${ }^{17}$

LDH is a cytoplasmic hydrogen transfer enzyme that is comprised of four peptide chains: two each of muscle (M) and heart $(\mathrm{H})$ type. Carcinogenesis affects the carbohydrate mechanism by interfering with the regeneration of NAD+ by decreasing lactate to pyruvate conversion. Furthermore, increased cellular degeneration, muscle degeneration by protein deficit, and induction process by tumor, all contribute to increased levels of LDH enzyme, making it a reliable indicator of malignant or PMD process. ${ }^{18}$

In our study, we estimated the salivary LDH without identifying its isoenzyme since our aim was to draw an easy and inexpensive diagnostic method. Estimation of isoenzyme required a gel electrophoresis method, which is expensive and time-consuming. Furthermore, Nagler et $\mathrm{al}^{19}$ in their study found that $75 \%$ of its salivary content originated from oral epithelial cells and appeared in the oral fluid due to desquamation of oral epithelial tissue and only $25 \%$ from the salivary gland. Still, to eliminate LDH enzyme from salivary gland origin, we excluded all the possible conditions, which nonspecifically increase the serum LDH level and in saliva, such as myocardial infarction, liver diseases, renal disease, and muscular dystrophy. ${ }^{18}$

Numerous studies ${ }^{11,20,21}$ have shown a significant association between periodontitis and salivary LDH level, but the level considerably decreased after conventional periodontal therapy. ${ }^{10,18}$ Thus, in our study, we included patients after evaluating the gingival and periodontal status using clinician-modified periodontal disease index, and for patients with periodontitis, the saliva sample was collected after the periodontal therapy.

The results of our study showed a progressive increase in the level of LDH in tobacco users without PMD to tobacco users with PMD when compared with healthy controls, suggesting that its level can be used as a prognostic biomarker in very early stages. There was a significant difference between control and PMD groups, and this result was in accordance with the study conducted by Shetty et $\mathrm{al}^{22}$ in which they had compared the control group, leukoplakia group, and oral cancer group. Furthermore, in our study, there was an increase in the LDH level from the control group to tobacco users. This finding was similar to the study done by De La Peña et $\mathrm{al}^{11}$; however, in their study, they had considered only smokers without giving importance to chewable tobacco. In contrast to our result, Nagler et $\mathrm{al}^{19}$ found a reduction of 41 to $57 \%$ in salivary LDH activity after a 3-hour exposure to cigarette smoke, but these studies could not reproduce the biological conditions of the oral cavity in the in vitro experimental model designed. Most importantly, the enzymes undergo denaturation at a temperature above $50^{\circ} \mathrm{C}$ and become inactive at a temperature above $70^{\circ} \mathrm{C} .{ }^{23}$ This might be one of the reasons for reduced level in their study since temperature of the mouth is raised to $900^{\circ} \mathrm{C}$ during a puff and falls to approximately $400^{\circ} \mathrm{C}$ between puffs. ${ }^{24}$

When the effect of tobacco is considered, its duration, frequency, and its form will play a major role in causing its effect on the oral cavity. Hence, in our study, we also estimated the change in the LDH level with respect to all the aforementioned factors. There was a significant increase in LDH level with increased duration and frequency and was more significant in the PMD group. However, duration and frequency alone may or may not have its effect on the LDH level. In our study, we observed a higher value in patients who consumed tobacco for lesser duration but with increased frequency and vice versa.

On comparing the LDH level among different PMD groups, patients with leukoplakia showed a higher level when compared with OSMF. In addition, while evaluating the effect of form of tobacco on the LDH level, we observed a higher mean value in the smoker group when compared with smokeless tobacco users. Till now, numerous studies have established the role of smokeless tobacco and leukoplakia. ${ }^{25}$ This suggests some interconnection between smoking, leukoplakia, and salivary LDH level. However, this study is not conclusive for the preceding statement because the sample size is small and unequally distributed.

\section{Conclusion}

In various research settings, it has been observed that salivary diagnostics have potential capabilities in the diagnosis and screening of oral precancer and cancer. This diagnostic capacity is based on the continuous and intimate contact between saliva and the mucosa, where cancer evolves. The results of this study along with the observations of the studies performed in the past related to salivary LDH biomarker lead us to conclude that estimation of salivary LDH could be a prognostic biomarker in identifying the patients with higher risk at a very early stage. The method being noninvasive, inexpensive, and simple can be used as a screening test and can help in educating patients about the harmful effects of tobacco as well as in assessing the potential for malignant transformation with reasonable accuracy. However, additional studies at rural and urban primary health care centers including larger patient groups would throw more light and substantiate this very interesting and useful analysis.

\section{Funding}

None.

\section{Disclaimer}

The MedIntel Services Pvt Ltd. and The South Asian Journal of Cancer neither endorse nor discourage the use of the product described in this publication.

\section{Conflict of Interest}

There are no conflicts of interest.

\section{References}

1 Prabhu SR, Johnson NW, Daftary DK, Oral Diseases in the Tropics. 1st ed. New York, NY: Oxford University Press; 1992

2 Nagler RM, Barak M, Peled M, Ben-Aryeh H, Filatov M, Laufer D. Early diagnosis and treatment monitoring roles of tumor markers Cyfra 21-1 and TPS in oral squamous cell carcinoma. Cancer 1999;85(5):1018-1025

3 Parkin DM, Bray F, Ferlay J, Pisani P. Estimating the world cancer burden: Globocan 2000. Int J Cancer 2001;94(2):153-156 
4 Napier SS, Speight PM. Natural history of potentially malignant oral lesions and conditions: an overview of the literature. J Oral Pathol Med 2008;37(1):1-10

5 Preeti S, Raut DK. Prevalence and pattern of tobacco consumption in India. Int Res J Soc Sci 2012;1:36-43

6 Mehrotra R, Gupta DK. Exciting new advances in oral cancer diagnosis: avenues to early detection. Head Neck Oncol 2011;3:33

7 Mohan M, Jagannathan N. Oral field cancerization: an update on current concepts. Oncol Rev 2014;8(1):244

8 Rajkumar K, Kumar AR, Ramyamalini V, Nandhini G, Kumar DT, Ashwini BK. Estimation of serological and salivary biomarkers in patients with oral squamous cell carcinoma, premalignant lesions and conditions. SRM Univ J Dent Sci 2010;1:14-19

9 Shpitzer T, Hamzany Y, Bahar G, et al. Salivary analysis of oral cancer biomarkers. Br J Cancer 2009;101(7):1194-1198

10 Merza KS, Alaaraji SB, Abdullah BH. Comparative study on lactate dehydrogenase and immunoglobulins in serum and saliva of acute leukemia and oral squamous cell carcinoma patients. Iraqi J Sci 2010;51:262-270

11 De La Peña VA, Diz Dios P, Tojo Sierra R. Relationship between lactate dehydrogenase activity in saliva and oral health status. Arch Oral Biol 2007;52(10):911-915

12 Recommendationsof the German Society for Clinical Chemistry. Standardisation of methods for the estimation of enzyme activities in biological fluids. Experimental basis for the optimized standard conditions. Z Klin Chem Klin Biochem 1972;10(6):281-291

13 Agrawal K, Rajderkar SS, Tuljapurkar V. Tobacco related cancers at a tertiary care hospital in Western India. Health Renaiss 2013;11:43-46

14 Silverman S Jr, Gorsky M. Epidemiologic and demographic update in oral cancer: California and national data-1973 to 1985. J Am Dent Assoc 1990;120(5):495-499

15 Llewellyn CD, Johnson NW, Warnakulasuriya KA. Risk factors for squamous cell carcinoma of the oral cavity in young people-a comprehensive literature review. Oral Oncol 2001;37(5):401-418
16 International Institute for Population Sciences, Mumbai and Ministry of Health and Family Welfare, Government of India. Global Adult Tobacco Survey India (GATS INDIA); 2009-2010. Available at: https://www.who.int/tobacco/surveillance/survey/ gats/gats_india_report.pdf?ua=1

17 Shah FD, Begum R, Vajaria BN, et al. A review on salivary genomics and proteomics biomarkers in oral cancer. Indian $\mathrm{J}$ Clin Biochem 2011;26(4):326-334

18 Pereira T, Shetty S, Pereira S. Estimation of serum lactate dehydrogenase level in patients with oral premalignant lesions/ conditions and oral squamous cell carcinoma: a clinicopathological study. J Cancer Res Ther 2015;11(1):78-82

19 Nagler RM, Klein I, Reznick AZ. The interaction between saliva and cigarette smoke and its devastating biological effects as related to oral cancer [in Hebrew]. Harefuah 2001;140(7):614-618, 677

20 Todorovic T, Dozic I, Vicente-Barrero M, et al. Salivary enzymes and periodontal disease. Med Oral Patol Oral Cir Bucal 2006;11(2):E115-E119

21 Dabra S, China K, Kaushik A. Salivary enzymes as diagnostic markers for detection of gingival/periodontal disease and their correlation with the severity of the disease. J Indian Soc Periodontol 2012;16(3):358-364

22 Shetty SR, Chadha R, Babu S, Kumari S, Bhat S, Achalli S. Salivary lactate dehydrogenase levels in oral leukoplakia and oral squamous cell carcinoma: a biochemical and clinicopathological study. J Cancer Res Ther 2012;8(8, Suppl 1) :S123-S125

23 Murray RK, Granner DK, Mayes PA, Harper's Illustrated Biochemistry. 26th ed. New York, NY: Lange Medical Publications/McGraw-Hill; 2003

24 Centers for Disease Control and Prevention, How Tobacco Smoke Causes Disease: The Biology and Behavioral Basis for SmokingAttributable Disease: A Report of the Surgeon General. Atlanta, GA: Centers for Disease Control and Prevention; 2010

25 Baric JM, Alman JE, Feldman RS, Chauncey HH. Influence of cigarette, pipe, and cigar smoking, removable partial dentures, and age on oral leukoplakia. Oral Surg Oral Med Oral Pathol 1982;54(4):424-429 